\title{
METODOLOGIA PARA DETERMINAÇÃO DE DIGLUCONATO DE CLORHEXIDINA EM CARCAÇAS DE FRANGO UTILIZANDO CLAE - PAR IÔNICO E AVALIAÇÃo DE RESÍDUOS DURANTE A REFRIGERAÇÃO E CONGELAMENTO ${ }^{1}$
}

\author{
Eduardo VICENTE ${ }^{2, *}$, Maria Cecília de Figueiredo TOLEDO ${ }^{3}$
}

\begin{abstract}
RESUMO
O uso do digluconato de clorhexidina (DGCH) na higienização de equipamentos e instalações na indústria de alimentos e o interesse de aplicação deste produto como sanitizante em carcaças de frango indicam a necessidade da avaliação de resíduos no alimento. Um método por cromatografia líquida de alta eficiência (CLAE) com pareamento de íons, incluindo extração com éter etílico em meio alcalino, foi desenvolvido para determinação de clorhexidina em carne de frango. O limite de quantificação do método $(0,6 \mu \mathrm{g} / \mathrm{g})$ e a recuperação média em carcaça $(75 \%$ - CV $10 \%)$, em pele $(72 \%$ - CV $7 \%)$ e na musculatura $(82 \%$ - CV $8 \%)$ foram considerados adequados aos propósitos do método. As análises de carcaças e pele tratadas, mantidas refrigeradas ou congeladas, permitiu constatar que ocorreu uma pequena redução nos niveis residuais de DGCH durante o período de armazenamento. Como prováveis causas desta diminuição devem ser considerados a interação com componentes polares da matriz, a perda juntamente com os fluidos liberados dos tecidos durante o armazenamento refrigerado ou no descongelamento de carcaças inteiras e a degradação da clorhexidina. A ausência deste sanitizante na musculatura após o armazenamento refrigerado indica que nas condições empregadas, o DGCH não atravessa a barreira da pele. Palavras-chave: digluconato de clorhexidina; cromatografia líquida; carcaças; frangos.
\end{abstract}

\section{SUMMARY}

HPLC - ION PAIRING DETERMINATION OF CHLORHEXIDINE DIGLUCONATE IN TREATED POULTRY CARCASSES. ANALYSIS DURING REFRIGERATION AND FREEZING. The use of the antimicrobial agent chlorhexidine digluconate in the sanitization of food industry equipment and installations, and the interest on its application to decontaminate poultry carcasses indicates the need to determine its residue in food. An ion pairing HPLC - UV analytical method including an ethyl ether extraction in alkaline medium was developed to measure clorhexidine residue in poultry meat. The limit of analytical quantitation $(0,6 \mu \mathrm{g} / \mathrm{g})$ and recoveries in carcasses $(75 \%-\mathrm{CV} 10 \%)$, skin $(72 \%-\mathrm{CV} 7 \%)$, and muscular tissue $(82 \%-\mathrm{CV} 8 \%)$ were appropriate to the purposes of the method application. The analysis of treated carcasses and skin, maintained refrigerated or frozen showed a slight decrease of the initial levels during storage. The interaction with polar components of matrix, the elimination with tissues fluid during refrigerated storage, the unfreezing step of the whole carcasses, and the degradation of the added chlorhexidine can be considered as the most probable cause for the decrease. The absence of residue in muscular tissue after refrigerated storage showed that the molecule practically did not cross the skin barrier.

Keywords: chlorhexidine digluconate; HPLC; poultry; carcasses.

\section{1 - INTRODUÇÃO}

A clorhexidina, uma bis-guanida com propriedades antimicrobianas, foi introduzida na década de 50 e tem sido amplamente utilizada na odontologia e nas áreas médica e veterinária $[4,13,14,19]$. Nas indústrias que manipulam produtos de origem animal ela tem sido empregada como desinfetante de mãos, equipamentos e superficies $[2,8]$.

As evidências da baixa toxicidade [9, 12], aliadas à eficiência antimicrobiana, levaram ao desenvolvimento de estudos para avaliar a aplicação da clorhexidina para o controle de microrganismos em diferentes alimentos. Resultados preliminares foram favoráveis ao emprego direto do digluconato de clorhexidina (DGCH) durante a maturação de queijos, pós-colheita em maçãs [10, 22] e para descontaminação de carcaças de frangos [24]. Em

\footnotetext{
Recebido para publicação em 23/11/2001. Aceito para publicação em 23/04/2003 (000780).

${ }^{2}$ Centro de Química, Instituto de Tecnologia de Alimentos - ITAL.

Av. Brasil, 2880 - Campinas-SP. CEP 13073-001 Fone: (OXX19)37431771.E-mail: evicente@ital.org.br

${ }^{3}$ Departamento de Ciência de Alimentos - Faculdade de Engenharia de Alimentos-FEA - UNICAMP. Cidade Universitária Campus "Zeferino Vaz". CEP 13001-970. Fone: (19) 3289-2168 - Fax: 3788-7890. E-mail: macecil@fea.unicamp.br

* A quem a correspondência deve ser enviada.
}

um estudo comparativo foi constatado que o DGCH foi um dos produtos mais eficientes, aumentando a vidaútil de carcaças de frango refrigeradas para 9 dias, ao passo que carcaças tratadas com outros sanificantes possibilitaram o armazenamento por no máximo 8 dias [17].

A aplicação do DGCH para a pulverização direta de carcaças de frango, suínos e bovinos foi permitida no Brasil, através da Autorização de Uso de Produto (AUP) № 184/93 [1]. Esta AUP foi revogada posteriormente e o pedido de registro indeferido [3], tendo em vista a possibilidade de resíduos no produto final, ausência de informações toxicológicas e a possibilidade de mascarar falhas no processo tecnológico, no que se refere aos valores microbiológicos.

Métodos analiticos foram desenvolvidos para determinação de DGCH em produtos farmacêuticos [7, 13, 23]. HUSTON et al. [14] efetuaram análises de DGCH em sangue e urina fazendo a extração com éter etílico em meio alcalino. BROUGHAM et al. [5] optaram pela partição com clorofórmio- $2 \%$ isopropanol em meio alcalino, seguido da extração para um meio aquoso fracamente ácido. Para análise em urina, a amostra foi percolada em cartucho de $\mathrm{C}_{18}$ e o DGCH eluído com metanol [11]. Um método para avaliação do nivel residual de DGCH em saliva foi desenvolvido por PESONEN et al. [18], onde pequenos volumes de saliva alcalinizada foram extraidos com acetonitrila, posteriormente separada da fração 
aquosa por centrifugação. Devido ao caráter fortemente iônico do DGCH, a maioria dos métodos utilizou cromatografia liquida de alta eficiência (CLAE) em fase reversa, com par iônico. Foram avaliadas fases móveis contendo os ácidos pentadecafluorooctanóico, tolueno-4-sulfônico, heptanossulfônico ou o heptanossulfonato de sódio como contra-íon [14]. A detecção foi feita em comprimento de onda de 260nm, ou em 220-230nm quando o DGCH foi determinado simultaneamente com o produto de degradação, 4-cloroanilina [11, 18, 20, 23].

A possibilidade da introdução do DGCH na descontaminação de carcaças torna necessário o estudo dos niveis residuais deste sanificante no alimento. Apesar das informações disponiveis indicarem a baixa toxicidade do DGCH, é importante conhecer a contribuição desta fonte adicional do xenobiótico e obter informações para uma adequada avaliação toxicológica do produto. Todavia, não existem métodos apropriados para a determinação de DGCH em tecidos animais. O presente trabalho tem como objetivos o desenvolvimento de metodologia para quantificação de DGCH em carcaças de frangos e também a avaliação de resíduos do antimicrobiano em carcaças tratadas com o sanitizante, durante a refrigeração e o congelamento.

\section{2 - MATERIAL E MÉTODOS}

\section{1 - Reagentes}

Alacalase Food Grade atividade 2,4L (Novo Nordisk), hexano, acetonitrila, metanol grau CLAE (Mallinckodt), éter etílico P. A. estabilizado com BHT (Carlo Erba), trietilamina, heptanossulfonato de sódio (Aldrich), ácido fosfórico 85\%, hidrogeno fosfato dissódico, ácido fórmico 98\% PA (Merck) e água desmineralizada em sistema Milli Q (Millipore). Digluconato de clorhexidina solução comercial a 20\% (Laboratório Enila) e solução padrão 20\% (Aldrich).

\section{2 - Instrumentação}

O equipamento utilizado foi um cromatógrafo líquido (Varian LC Star), equipado com bomba isocrática modelo 9002, detector UV variável $(\lambda 260 \mathrm{~nm})$ modelo 9050 e injetor Rheodyne com loop de $120 \mu \mathrm{L}$. As separações foram efetuadas em uma coluna Rainin Microsorb MV RP18 (250mm x 4,6mm di; com partículas de $5 \mu \mathrm{m}$, silanizada), sendo a temperatura mantida a $30^{\circ} \mathrm{C} \mathrm{com}$ o auxílio do aquecedor de coluna (Pharmacia s 5/20). A fase móvel foi constituída de acetonitrila-tampão $(0,1 \mathrm{M}$ $\mathrm{Na}_{2} \mathrm{HPO}_{4}-0,005 \mathrm{M}$ heptanossulfonato de sódio-0,05M trietilamina-ácido fosfórico pH 2,5), na proporção 33:67, com fluxo $1,0 \mathrm{~mL} / \mathrm{min}$.

\section{3 - Tratamento das amostras}

Para conhecimento dos niveis residuais de clorhexidina após tratamento nas condições reais de operação nos abatedouros, desenvolveu-se um experimento sob condições controladas. Utilizando uma solu- ção comercial do DGCH a 20\%, foi preparada uma diluição aquosa na proporção 1:500, resultando numa concentração final de $0,4 \mathrm{~g} / \mathrm{L}$. Um volume total de 350L dessa solução foi utilizado para tratar 38 carcaças, com um peso unitário médio de $1501 \mathrm{~g} \pm 20 \mathrm{~g}$. As carcaças utilizadas foram separadas da linha de produção antes da etapa de embalagem. O tratamento foi feito pela imersão total das mesmas na solução, por cerca de 2 segundos. Em seguida, estas foram colocadas em caixas plásticas vazadas, ali permanecendo durante 20 minutos, para que o excesso da solução fosse eliminado. As carcaças foram aleatoriamente reunidas em grupos compostos por cinco unidades, cujos pesos variaram entre 7380 a $7680 \mathrm{~g}$ e depois embaladas em sacos plásticos. Paralelamente, cinco carcaças sem qualquer tratamento foram embaladas da mesma forma para servir como amostra controle.

Para a avaliação dos niveis residuais de clorhexidina em pele, foram separados da linha de produção vinte e um cortes de peito com pele. As amostras foram, a seguir, tratadas com a mesma solução de clorhexidina $0,4 \mathrm{~g} / \mathrm{L}$, também utilizando imersão por 2 segundos. Destes cortes foram separadas as peles, incluindo seus anexos lipídicos, cujo peso unitário médio era de $92 \mathrm{~g} \pm 9 \mathrm{~g}$. A seguir, as peles foram embaladas em sacos plásticos, formando grupos de três unidades, que apresentaram pesos na faixa de $240 \mathrm{~g}$ a $314 \mathrm{~g}$. As peles de outros três cortes de peito, sem qualquer tratamento, foram embaladas da mesma forma, para utilização como amostra testemunha.

\section{4 - Homogeneização das amostras}

Anteriormente à homogeneização das carcaças foi efetuada a remoção manual dos ossos e apenas foram mantidas a musculatura e pele. Na etapa seguinte a amostra foi passada duas vezes em moedor de carne e processada por 10 minutos em "cutter" (Hobart), até a obtenção de um pasta homogênea.

\section{5 - Armazenamento}

\subsection{1 - Amostras refrigeradas}

Parte das amostras de carcaças e peles foram tratadas no abatedouro e em seguida homogeneizadas. O acompanhamento dos resíduos foi feito após 0, 2, 4, 6, 8 e 12 dias, a contar do dia do tratamento. Durante este periodo as amostras foram mantidas em temperatura de $5^{\circ} \mathrm{C} \pm 2^{\circ} \mathrm{C}$. As análises em carcaça foram efetuadas em triplicata e na pele em duplicata, utilizando o método desenvolvido.

Amostras de carcaça e pele tratadas foram armazenadas inteiras e analisadas após 6 e 11 dias de refrigeração $\left(5^{\circ} \mathrm{C} \pm 2^{\circ} \mathrm{C}\right)$. A homogeneização ocorreu somente no momento da análise. Outras 3 carcaças tratadas foram armazenadas inteiras por 12 dias a $5^{\circ} \mathrm{C} \pm 2^{\circ} \mathrm{C}$. Em seguida a musculatura do peito foi separada da pele e dos ossos, homogeneizada e analisada em triplicata, a fim de verificar a migração da clorhexidina aplicada na superficie. 


\subsection{2 - Amostras congeladas}

As amostras de carcaça tratadas foram congeladas $\left(-20{ }^{\circ} \mathrm{C} \pm 2{ }^{\circ} \mathrm{C}\right)$ inteiras no mesmo dia do tratamento $\mathrm{e}$ analisadas após 15, 30, 60 e 90 dias. As amostras correspondentes a 15 dias de armazenamento foram mantidas congeladas depois da homogeneização, para posterior análise após 30, 60 e 90 dias. As demais amostras permaneceram inteiras até o momento da análise.

\section{6 - Método analítico}

Foram pesados $5 \mathrm{~g}$ de amostra homogeneizada em um tubo de centrífuga com capacidade para $50 \mathrm{~mL}$ e com tampa de polietileno. Adicionaram-se sobre a amostra $200 \mu \mathrm{L}$ de alcalase, mantendo-se o tubo a $45^{\circ} \mathrm{C}$ por $30 \mathrm{~min}$, com agitação intermitente, até a liquefação da amostra. Após a digestão enzimática foram acrescentados $2 \mathrm{~g}$ de cloreto de sódio, $15 \mathrm{~mL}$ de hidróxido de sódio $1 \mathrm{~N}$ e $25 \mathrm{~mL}$ de éter etílico. O tubo foi mantido sob agitação por $1 \mathrm{~h}$, em agitador modelo Wagner (30 ciclos/min). A seguir, foi feita a centrifugação a 2000rpm/10min e a fração superior foi recolhida em outro tubo de $50 \mathrm{~mL}$. Seqüencialmente, foram adicionados outros $20 \mathrm{~mL}$ de éter etílico ao primeiro tubo, que foi agitado por 1 minuto e centrifugado a 2000rpm/10min. A fração superior foi então separada e reunida com a anterior, descartandose o tubo com a fração aquosa inferior. O éter recolhido nas duas centrifugações foi totalmente evaporado em fluxo de ar comprimido $/ 50^{\circ} \mathrm{C}$, permanecendo apenas o extrato lipídico. Ao tubo foram adicionados $20 \mathrm{~mL}$ de hexano, $30 \mathrm{~mL}$ de metanol e $200 \mu \mathrm{L}$ de ácido fórmico. O tubo foi vigorosamente agitado por 1 minuto e deixado em repouso durante 10 minutos em freezer $\left(-20^{\circ} \mathrm{C}\right)$. O hexano que permaneceu na fase superior foi descartado e a fração inferior mantida. Este processo foi repetido outras 2 vezes, utilizando $10 \mathrm{~mL}$ de hexano em cada partição. A fração inferior foi evaporada até a secura, com fluxo de ar comprimido/ $50^{\circ} \mathrm{C}$. O resíduo foi dissolvido em $5 \mathrm{~mL}$ de fase móvel, filtrado em membrana de $0,45 \mu \mathrm{m}$ e a seguir injetado em cromatógrafo líquido com detector UV (260nm).

Para amostras de pele, cujo teor de proteína é baixo e o conteúdo lipídico elevado, não foi necessária a digestão com alcalase. O éter etílico, cloreto de sódio e o hidróxido de sódio foram diretamente adicionados à amostra e o procedimento seguido sem qualquer outra modificação. A separação cromatográfica foi efetuada em coluna de fase reversa $\mathrm{C}_{18}$ silanizada (partículas de $5 \mu$, $250 \mathrm{~mm} \times 4 \mathrm{~mm}$ di), com fase móvel composta de acetonitrila-tampão $\left(0,1 \mathrm{M} \mathrm{Na}_{2} \mathrm{HPO}_{4}-0,005 \mathrm{M}\right.$ heptanossulfonato de sódio-0,05M trietilamina - pH 2,5 corrigido com ácido orto-fosfórico P. A.), na proporção 33:67, com fluxo $1,0 \mathrm{~mL} / \mathrm{min}$.

A confirmação da identidade foi possivel pela análise por CLAE - detector de arranjo de diodos (bomba LC1OAD, forno de colunas CTO 10 A, detector SPD M1OA fabricados pela Shimadzu), através da comparação dos espectros de absorbância (190-400nm) de picos com tempo de retenção equivalente ao padrão de clorhexidina.
Foram utilizadas a mesma coluna, fase móvel e condições cromatográficas descritas no método analitico.

\section{7 - Avaliação do desempenho do método}

Para avaliação da metodologia foram feitas fortificações de amostras não tratadas, utilizando-se soluções aquosas de DGCH. Amostras homogeneizadas de musculatura do peito foram fortificadas com 1, 2, 4, 6, 8 e $10 \mu \mathrm{g} / \mathrm{g}$ de clorhexidina. Amostras de carcaças inteiras homogeneizadas (musculatura e pele) foram fortificadas

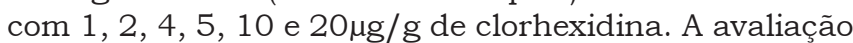
do método em pele do peito foi feita com fortificações de

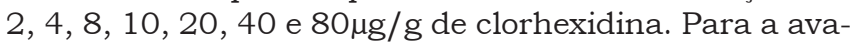
liação estatística dos dados foram utilizados análise de variância e o teste de Tukey - Diferença Minima Significativa, ao nivel de significância 5\%.

\section{8 - Limites de detecção, quantificação e precisão do método}

O limite de detecção do método (LD) foi determinado pela análise de 8 repetições de amostras fortificadas com $1,0 \mu \mathrm{g} / \mathrm{g}$ de $\mathrm{DGCH}$, de acordo com procedimento descrito por DE BRUIN et al. [6]. O desvio padrão da média dos resultados foi multiplicado pelo valor de $t$ de Student para uma confiabilidade de $99 \%$ segundo os graus de liberdade apropriados. Para 8 repetições e sete graus de liberdade o valor $t$ de Student tabelado é de 2,998. O limite de quantificação do método (LQM) foi estabelecido com base em KEITH et al. [15] e LONG \& WINEFORDNER [16], que o definem como 10 vezes o valor do desvio padrão. A precisão do método foi calculada pelo coeficiente de variação (CV\%), calculado a partir das determinações de amostras de pele, carcaça homogeneizada ou musculatura do peito, fortificadas em diferentes niveis com quatro repetições em cada nivel. A quantificação foi feita por calibração externa.

\section{3 - RESULTADOS E DISCUSSÃO}

\section{1 - Desenvolvimento do método}

Um dos maiores obstáculos para o desenvolvimento de um método apropriado para analisar resíduos de DGCH em tecidos animais é o fato dos mesmos serem sólidos e ricos em lipídios. As diversas metodologias que são descritas na literatura [5, 11, 14, 18] foram desenvolvidas em matrizes liquidas ou fluidas, onde a extração se inicia com uma partição liquido-liquido em meio alcalino.

Devido ao caráter iônico da clorhexidina, que interage com estruturas polares da amostra sólida, a extração da molécula na forma de digluconato exigiu o emprego de solventes aquosos. A digestão com a alcalase, uma endopeptidase, foi capaz de promover a desnaturação das proteinas, tornando a amostra mais fluida e com uma pequena quantidade de sólidos de tamanho reduzido. Esta enzima foi selecionada por sua eficiência, atividade em ampla faixa de $\mathrm{pH}$ e temperatura, além de ser disponivel comercialmente. Na etapa seguinte, a utiliza- 
ção de hidróxido de sódio $1 \mathrm{~N}$, elevando o $\mathrm{pH}$ acima do valor de $\mathrm{pK}_{\mathrm{a}} 10,3$, [14], converteu a clorhexidina a sua forma neutra, solúvel em solventes orgânicos. Para a extração da amostra digerida e alcalinizada foram avaliados o clorofórmio, cloreto de metileno, acetato de etila e o éter etílico, sendo que apenas o último favoreceu a partição e a evaporação que seria necessária na etapa posterior. A centrifugação foi imprescindivel para separar as partículas sólidas da amostra e quebrar a emulsão formada durante a agitação. O cloreto de sódio adicionado nesta etapa teve como função auxiliar a quebra da emulsão e diminuir a afinidade do éter etílico pela água. A estabilidade da clorhexidina permitiu a evaporação do solvente com aquecimento e com fluxo de ar comprimido. Os componentes lipídicos dos tecidos foram extraídos pelo éter e permaneceram após a evaporação. A partição metanol/hexano foi introduzida para a remoção desta gordura. Foi necessário empregar a baixa temperatura para reduzir a miscibilidade do hexano no metanol. Os lipidios foram eliminados juntamente com o hexano, permanecendo a clorhexidina na fase metanólica. O ácido fórmico nesta etapa teve a função de eliminar possíveis resíduos de hidróxido de sódio transferidos juntamente com o éter. Após a evaporação do metanol, o extrato foi solubilizado na fase móvel, onde o $\mathrm{pH} 2,5$ permitiu que a molécula retornasse à sua forma ionizada. O heptanossulfonato de sódio presente na fase móvel atuou como contra-ion e permitiu a separação cromatográfica em coluna de fase reversa $\mathrm{C}_{18}$.

\section{2 - Avaliação do desempenho do método}

A resposta do detector UV (260nm) ao DGCH foi li-

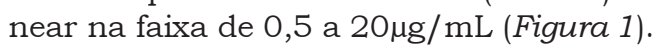

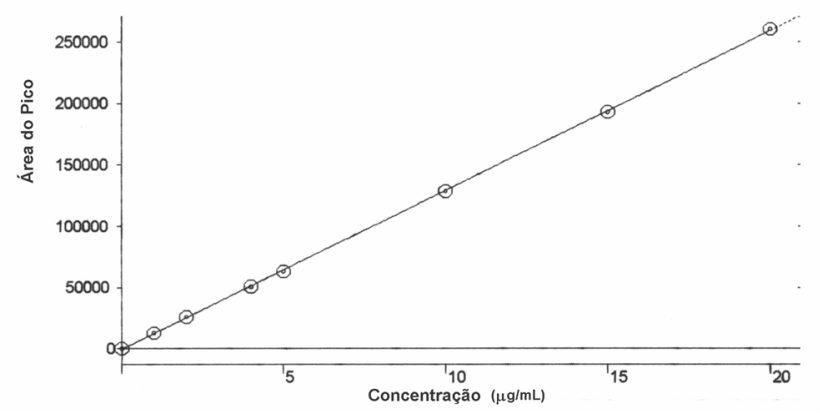

FIGURA 1. Linearidade de resposta a diferentes concentrações de digluconato de clorhexidina determinadas por CLAEdetector UV (260nm).

A linearidade da resposta do detector pode ser expressa pela equação:

$Y=12978 X-685$

onde: $\mathrm{Y}=$ Área do pico; $\mathrm{X}=$ Concentração $(\mu \mathrm{g} / \mathrm{g})$

Coeficiente de Correlação $\left(r^{2}\right)=0,999$
O LD calculado foi de $0,2 \mu \mathrm{g} / \mathrm{g}$, enquanto o LQM foi de $0,6 \mu \mathrm{g} / \mathrm{g}$. As recuperações de amostras de pele, carcaça total e musculatura fortificadas são apresentadas na Tabela 1. Os resultados indicaram que não houve diferença significativa nas recuperações entre os diferentes niveis adicionados à pele, com média de $72 \%$ e CV de $7,38 \%$ Em carcaças, a diferença somente foi significativa entre os niveis de $1 \mu \mathrm{g} / \mathrm{g}$ e $10 \mu \mathrm{g} / \mathrm{g}$, com valor médio de $75 \%$ e CV 10,08\%. Nas análises em musculatura ocorreu diferença significativa entre os niveis mais baixos $(1,2,4$ e $6 \mu \mathrm{g} / \mathrm{g})$ e os niveis mais altos (8 e $10 \mu \mathrm{g} / \mathrm{g})$, com recuperação média de $83 \%$ e CV 8,0\%.

TABELA 1. Recuperação de digluconato de clorhexidina adicionado a diferentes tecidos de frangos.

\begin{tabular}{cccccc}
\hline \multicolumn{2}{c}{ Musculatura $^{1}$} & \multicolumn{2}{c}{ Pele $^{2}$} & \multicolumn{2}{c}{ Carcaça total $^{1}$} \\
\hline $\begin{array}{c}\text { Nível de } \\
\begin{array}{c}\text { Fortificação } \\
(\mu \mathrm{g} / \mathrm{g})\end{array}\end{array}$ & $\begin{array}{c}\text { Recuperação } \\
(\%)\end{array}$ & $\begin{array}{c}\text { Nível de } \\
\text { Fortificação } \\
(\mu \mathrm{g} / \mathrm{g})\end{array}$ & $\begin{array}{c}\text { Recuperação } \\
(\%)\end{array}$ & $\begin{array}{c}\text { Nível de } \\
\text { Fortificação } \\
(\mu \mathrm{g} / \mathrm{g})\end{array}$ & $\begin{array}{c}\text { Recuperação } \\
(\%)\end{array}$ \\
\hline 1 & $80 \pm 1$ & 2 & $66 \pm 6$ & 1 & $67 \pm 6$ \\
2 & $73 \pm 8$ & 4 & $67 \pm 8$ & 2 & $75 \pm 10$ \\
4 & $79 \pm 3$ & 8 & $73 \pm 3$ & 4 & $73 \pm 9$ \\
6 & $83 \pm 1$ & 10 & $76 \pm 4$ & 5 & $74 \pm 5$ \\
8 & $90 \pm 2$ & 20 & $72 \pm 7$ & 10 & $79 \pm 5$ \\
10 & $90 \pm 4$ & 40 & $75 \pm 1$ & 20 & $80 \pm 4$ \\
---- & ---- & 80 & $75 \pm 2$ & --- & --- \\
\hline
\end{tabular}

${ }^{1}$ Análise de amostras pelo método desenvolvido incluindo a digestão enzimática. Média de 4 repetições.

stras pelo método desenvolvido sem a digestão enzimática. Média de 4 repetições.

\section{3 - Análises em amostras tratadas no abatedouro}

Os residuos de clorhexidina foram determinados nas carcaças e peles tratadas com DGCH, armazenadas inteiras ou previamente homogeneizadas, sob refrigeração $\left(5 \pm 2^{\circ} \mathrm{C}\right)$ ou congelamento $\left(-20^{\circ} \mathrm{C}\right)$. As Tabelas 2 e 3 apresentam os resultados das análises efetuadas durante 12 dias nas amostras refrigeradas e a Tabela 4 mostra os niveis de DGCH encontrados nas amostras congeladas durante os 90 dias de armazenamento.

Os resultados da Tabela 2 indicam que tanto nas carcaças inteiras como nas amostras homogeneizadas os resíduos de DGCH diminuíram durante o armazenamento a $5^{\circ} \mathrm{C}$. No caso das carcaças inteiras a redução foi bem mais acentuada, chegando a cerca de $50 \%$ no final dos 12 dias.

TABELA 2. Resíduos de digluconato de clorhexidina em carcaças armazenadas a $5^{\circ} \mathrm{C}$.

\begin{tabular}{ccc}
\hline Dias após o tratamento & \multicolumn{2}{c}{ Clorhexidina $(\mu \mathrm{g} / \mathrm{g})^{2}$} \\
\cline { 2 - 3 } & Homogeneizadas $^{1}$ & Inteiras $^{2}$ \\
\hline 0 & Média $^{3}$ & Média $^{3}$ \\
2 & $14,2 \pm 0,9$ & $14,2 \pm 0,9$ \\
4 & $14,9 \pm 0,7$ & $\mathrm{NR}^{4}$ \\
6 & $14,1 \pm 0,9$ & $\mathrm{NR}$ \\
8 & $14,1 \pm 0,4$ & $8,0 \pm 0,5$ \\
12 & $13,2 \pm 0,5$ & $\mathrm{NR}$ \\
& $12,3 \pm 0,7$ & $7,0 \pm 0,7$ \\
\hline
\end{tabular}

Média de 3 determinações ${ }^{4}$ Não Realizado 
Em relação às carcaças congeladas (Tabela 3), as variações observadas nos teores de DGCH não indicam uma tendência definida e podem ter ocorrido devido à homogeneização irregular das amostras e/ou à heterogeneidade das carcaças inteiras em relação ao nivel residual de clorhexidina. Os resultados obtidos sugerem que não houve diminuição dos niveis residuais de DGCH durante o armazenamento, pelo menos para as amostras homogeneizadas.

TABELA 3. Resíduos de digluconato de clorhexidina em carcaças de frango armazenadas a $-20^{\circ} \mathrm{C}$.

\begin{tabular}{ccc}
\hline \multirow{2}{*}{ Dias após o tratamento } & \multicolumn{2}{c}{ Clorhexidina $(\mu \mathrm{g} / \mathrm{g})$} \\
\cline { 2 - 3 } & Homogeneizadas $^{1}$ & Inteiras \\
\hline & Média $^{1}$ & Média $^{1}$ \\
\hline 15 & $6,6 \pm 0,1$ & $6,6 \pm 0,1$ \\
30 & $6,8 \pm 0,3$ & $6,7 \pm 0,2$ \\
60 & $8,3 \pm 0,2$ & $7,7 \pm 0,5$ \\
90 & $6,9 \pm 0,2$ & $5,0 \pm 0,5$ \\
\hline
\end{tabular}

Média de 3 determinações

$\mathrm{Um}$ teor relativamente maior de $\mathrm{DGCH}$ foi determinado em peles de frango (Tabela 4) relativamente às carcaças inteiras, o que era esperado tendo em vista a aplicação superficial do sanitizante. Tanto nas amostras homogeneizadas quanto nas peles inteiras a quantidade de resíduos diminuiu gradualmente durante o armazenamento refrigerado.

TABELA 4. Resíduos de digluconato de clorhexidina em peles de frango armazenadas a $5^{\circ} \mathrm{C}$.

\begin{tabular}{ccc}
\hline Dias após tratamento & \multicolumn{2}{c}{ Clorhexidina $(\mu \mathrm{g} / \mathrm{g})$} \\
\cline { 2 - 3 } & Homogeneizadas $^{1}$ & Inteiras \\
\hline & $32,1 \pm 0,8$ & Média $^{1}$ \\
\hline 0 & $27,4 \pm 0,4$ & $32,1 \pm 0,8$ \\
2 & $29,9 \pm 0,0$ & $\mathrm{NR}^{2}$ \\
4 & $28,3 \pm 1,0$ & $\mathrm{NR}$ \\
6 & $27,4 \pm 1,2$ & $29,8 \pm 3,0$ \\
8 & $24,2 \pm 0,4$ & $\mathrm{NR}$ \\
12 & & $20,0 \pm 0,5$ \\
\hline
\end{tabular}

${ }^{1}$ Média de 2 determinações

A redução dos niveis do sanitizante nos tecidos armazenados inteiros ou homogeneizados pode ser atribuída, entre outros, a interações irreversiveis do DGCH com grupos polares e/ou iônicos da matriz e/ou sua solubilização nos fluidos liberados pelos tecidos durante o armazenamento a $5^{\circ} \mathrm{C}$ ou descongelamento.

Uma possivel degradação do composto também não deve ser descartada, muito embora acredite-se que esta seja pequena, tendo em vista a estabilidade do DGCH e as baixas temperaturas empregadas.

É importante ressaltar que a perda de liquidos durante o processo de descongelamento das carcaças foi visivelmente menor que a observada durante o período de armazenamento sob refrigeração, o que pode explicar a maior redução dos niveis de DGCH nas amostras refrigeradas relativamente àquelas mantidas congeladas.

A possibilidade de ocorrência de interações entre o DGCH e estruturas dos tecidos está de acordo com resultados relatados por GELINAS \& GOULET [12]. Estes autores avaliaram a neutralização de desinfetantes por matéria orgânica e constataram que a atividade do acetato de clorhexidina era moderadamente afetada na presença de leite em pó, sangue bovino desidratado e farinha de peixe.

Em todas as situações avaliadas é importante considerar que, apesar de as amostras terem apresentado pesos semelhantes, as quantidades de DGCH que foram retidas nas mesmas podem ter variado em função de caracteristicas peculiares a cada unidade utilizada para compor a amostra. Este fato pode ter sido parcialmente responsável pela inconsistência de alguns resultados, impedindo uma melhor caracterização do comportamento dos resíduos durante o armazenamento de carcaças e peles inteiras. A análise seqüencial de alíquotas da mesma amostra previamente homogeneizada minimizou esta variável, permitindo uma melhor avaliação dos resultados.

Através da análise da musculatura do peito $(n=3)$, separada de carcaças tratadas após o armazenamento por 12 dias a $5^{\circ} \mathrm{C}$, constatou-se que os niveis residuais de DGCH estavam abaixo do limite de quantificação do método $(0,6 \mu \mathrm{g} / \mathrm{g})$, o que indica que a migração do sanitizante através da pele foi minima.

O método desenvolvido permitiu a quantificação dos resíduos nos diferentes tecidos. Os cromatogramas característicos de amostras de pele (Figura 2) e carcaça (Figura 3) tratadas com DGCH, assim como os respectivos controles, mostram que existem poucos interferentes com tempo de retenção próximo à clorhexidina.

A partir do 8 dia de armazenamento sob refrigeração, percebeu-se nas amostras não tratadas o desenvolvimento de odores decorrentes de decomposição. Nas amostras tratadas, nenhum odor estranho foi notado até o final do experimento, o que é um indicativo da eficiência do sanitizante, muito embora a avaliação microbiológica não tenha sido objeto deste estudo.

\section{4 - CONCLUSÕES}

A proposta inicial de desenvolvimento de método analítico para determinação do $\mathrm{DGCH}$ foi plenamente atingida. O procedimento desenvolvido proporcionou recuperação e sensibilidade adequadas aos niveis encontrados nas amostras e permitiu analisar residuos em tecidos com diferentes teores de gordura. O consumo de solventes e reagentes é pequeno e os equipamentos exigidos são relativamente simples. Tendo em vista a simplicidade da vidraria utilizada, várias extrações podem ser feitas simultaneamente.

Os residuos de DGCH permaneceram nas carcaças após o tratamento com o sanificante e persistiram durante a refrigeração ou congelamento. 

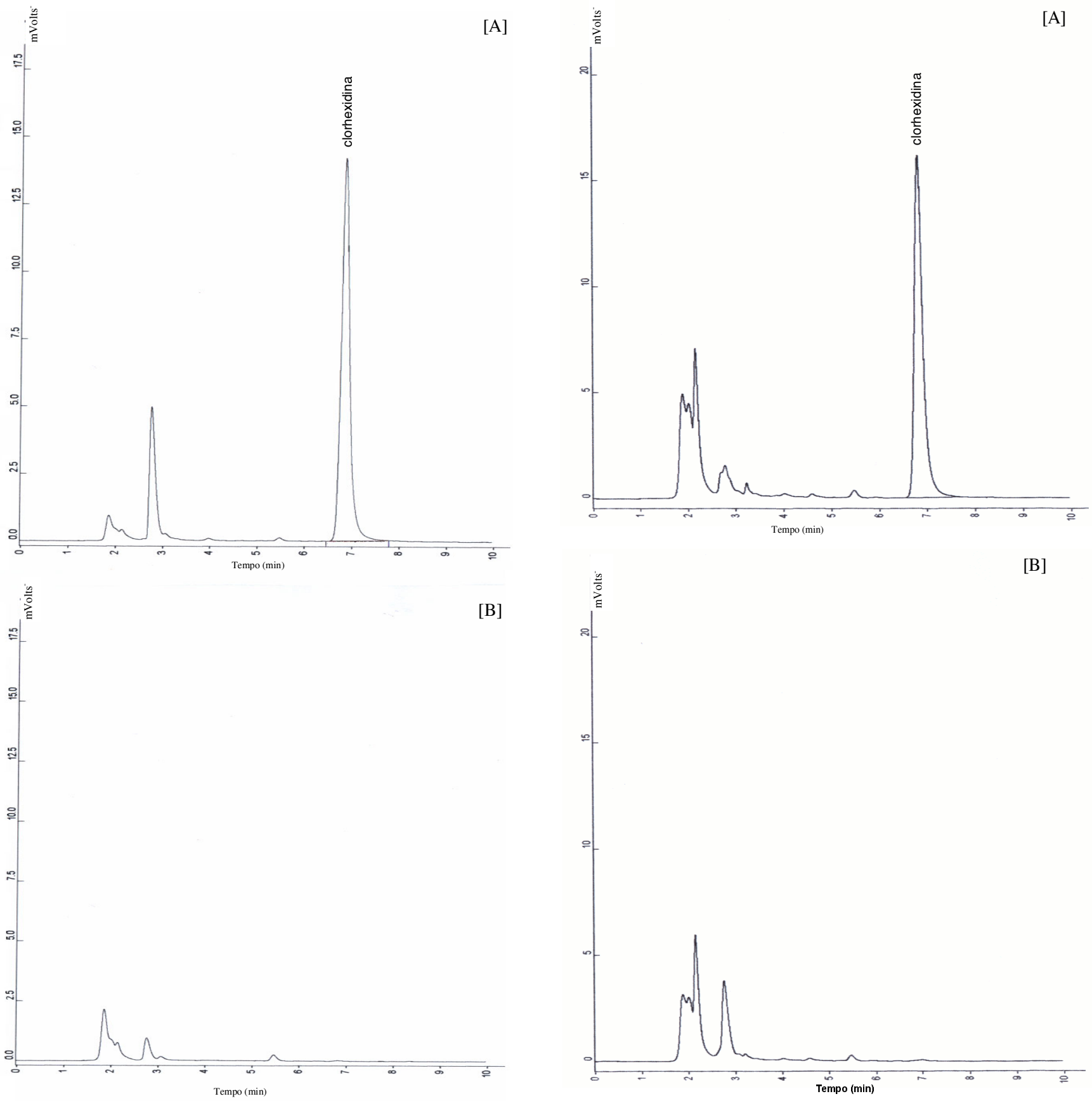

FIGURA 2. Cromatogramas por CLAE típicos de pele de frango. Diluição final das amostras $5 \mathrm{~g} / 10 \mathrm{~mL}$. Condições cromatográficas: coluna $\mathrm{C}_{18}$ silanizada (250mm x 4,6mm di); fluxo $1,0 \mathrm{~mL} / \mathrm{min}$; fase móvel acetonitrila-tampão fosfato( $0,1 \mathrm{M}$ $\mathrm{Na}_{2} \mathrm{HPO}_{4}-0,005 \mathrm{M}$ heptanossulfonato de sódio-0,05M trietilamina- ác. fosfórico pH 2,5) na proporção 67:33. [A] Amostra tratada com solução de digluconato de clorhexidina com o pico equivalente a $16,1 \mu \mathrm{g} / \mathrm{mL}, \mathrm{t}_{\mathrm{R}}=6,73 \mathrm{~min}$. [B] Amostra não tratada.

FIGURA 3. Cromatogramas por CLAE típicos de carcaça de frango. Diluição final das amostras $5 \mathrm{~g} / 5 \mathrm{~mL}$. Condições cromatográficas: coluna $\mathrm{C}_{18}$ silanizada ( $250 \mathrm{~mm} \times 4,6 \mathrm{~mm}$ di); fluxo $1,0 \mathrm{~mL} / \mathrm{min}$; fase móvel acetonitrila-tampão fosfato $(0,1 \mathrm{M}$ $\mathrm{Na}_{2} \mathrm{HPO}_{4}-0,005 \mathrm{M}$ heptanossulfonato de sódio-0,05M trietilamina- ác. fosfórico pH 2,5) na proporção 67:33. [A] Amostra tratada com solução de digluconato de clorhexidina com o pico equivalente a $14,2 \mu \mathrm{g} / \mathrm{mL}, \mathrm{t}_{\mathrm{R}}=6,69 \mathrm{~min}$. [B] Amostra não tratada. 
Considerando que a degradação térmica do sanitizante pode formar a 4-cloroanilina, potencialmente carcinogênica, sugere-se que sejam feitos estudos complementares para a determinação do produto de degradação em carcaças tratadas com DGCH e submetidas a processamento térmico.

\section{5 - REFERÊNCIAS BIBLIOGRÁFICAS}

[1] BRASIL. Ministério da Agricultura, Abastecimento e Reforma Agrária DOI/DIPOA. Autorização de uso de produto (AUP) No 184/93. Brasília, DF, 25 out. 1993.

[2] BRASIL. Ministério da Agricultura e do Abastecimento DOI/ DIPOA. Autorização de uso de produto (AUP) № 255/ 99. Brasília, DF, 07 jul. 1999.

[3] BRASIL. Ministério da Saúde. Portaria No 264 de 13 de Outubro. Diário Oficial da União, Brasília, DF, 19 out. seção 1, n. 201, p. 16564, 1995.

[4] BRITISH PHARMACOPOEIA. Office of the British Pharmacopoeia. London: Her Majesty's Stationery Office. v. 1. 398p., 1993.

[5] BROUGHAM, L.R., CHENG, H., PITTMAN, K.A. Sensitive highperformance liquid chromatographic method for the determination of chlorhexidine in human serum and urine. Journal of Chromatography v. 383, p. 365-373, 1986.

[6] De BRUIN, L.S., JOSEPHY, P. D., PAWLISZYN, J.B. 1998. Solid Phase Microextraction of monocyclic Aromatic Amines from Biological Fluids. Analytical Chemistry v. 70, n. 9, p. 1986-1992, 1998.

[7] DOUB, W.H., RUHL, D.D., HART, B., MEHELIC, P. R., REVELLE, L.K. Gradient liquid chromatographic method for the determination of chlorhexidine and its degradation products in bulk material. Journal of Association of Official Analytical Chemists International v. 79, $\mathrm{n}$. 3, p. 636-639, 1996.

[8] FINZI, M, COSTA, C. Microbiological contamination in food processing plants. Preventive measures. Rivista della Societa Italiana di Scienza dell Alimentazione, v. 8, n. 4, p. 258-261, 1979.

[9] FOULKES, D.M. Some toxicological observations on chlorhexidine. Journal of Periodontal Research v. 8, p. 55-60, 1973.

[10] FURTADO, M.M., SAMPAIO, M.H.D., NUNES, L.G. Avaliação do uso da clorhexidina no tratamento da salmoura e da casca do queijo curado: Relatório técnico. UFV, Viçosa. 10p., 1989.

[11] GAFFNEY, M., COOKE, M., SIMPSON, R. Improved method for the determination of chlorhexidine in urine. Journal of Chromatography v. 306, p. 303-313, 1984.

[12] GELINAS, P. , GOULET, J. Neutralization of the activity of eight disinfectants by organic matter. Journal of Applied Microbiology v. 54, p. 243-247, 1983.
[13] HARBISON, M., HAMMER, S.M. Inactivation of human immunodeficiency virus by betadine products and chlorhexidine. Journal of Acquired Immune Deficiency Syndomes v. 2, p. 16-20, 1989.

[14] HUSTON, C.E., WAINWRIGHT, P. , COOKE, M., SIMPSON, R. High-performance liquid chromatographic method for the determination of chlorhexidine. Journal of Chromatography v. 237, p. 457-464, 1982.

[15] KEITH, L.H., CRUMMETT,W., DEEGAN Jr., J., LIBBY, R.A., TAYLOR, J.K., WENTLER, G. Principles of environmental analysis. Analytical Chemistry v. 55, p. 2210-2218, 1983.

[16] LONG, G.L., WINEFORDNER, J.D. Limit of detection. A closer look at the IUPAC definition. Analytical Chemistry v. 55, p. 712A-724A, 1983.

[17] MACHADO, R.A. Microbiota bacteriana no processamento industrial de frangos e sua influência na vida útil de carcaças refrigeradas. 166p., 1992. Dissertação de Doutorado, Faculdade de Ciências Farmacêuticas, Universidade de São Paulo, São Paulo.

[18] Pesonen, T., holmalahti, J., POHJola, J. Determination of chlorhexidine in saliva using highperformance liquid chromatography. Journal of Chromatography B Biomedical Applications v. 10, p. 222-225, 1995.

[19] REYNOLDS, J.E.F., PRASAD, A.B., editors. Martindale. The Extra Pharmacopoeia. London: The Pharmaceutical Press. 555p. 1982.

[20] RICHARD, A., ElBAZ, M., ANDERMANN, G. Determination of 4-chloroaniline and chlorhexidine digluconate by ion-pair reversed-phase highperformance liquid chromatography. Journal of Chromatography CHROM v. 16, n. 870, p. 356359, 1984.

[21] RINDOM-SCHIOTT, C., LÖE, H., BRINER, W.W. Two year oral use of chlorhexidine in man. IV. Effect on various medical parameters. Journal of Periodontal Research v. 11, p. 158-164, 1976.

[22] SANHUEZA, R.M.V. Efeito do digluconato de clorhexidina e tiabendazólio no controle da podridão causada por Penicillium expansum em maçãs CV. Fuji e Golden Delicious. Relatório técnico. EmbrapaCNPFT, Pelotas. 6p., 1991.

[23] STEVENS, L.E., DURRWACHTER, J.R., HELTON, D.O. Analysis of chlorhexidine sorption in soft contact lenses by catalytic oxidation of $\left[{ }^{14} \mathrm{C}\right]$ chlorhexidine and by liquid chromatography. Journal of Pharmaceutical Sciences v. 75 , n. 1 , p. 83-86, 1986.

[24] TERRA, N. N. , LENZ, G., GARCIA, S. Avaliação do uso do digluconato de clorhexidina na conservação de carcaças resfriadas de frango. Relatório técnico confidencial. Centro de Ciências Rurais, Universidade Federal de Santa Maria, Santa Maria. 8p., 1989. 